\title{
MENSURACÃO DE RESULTADOS EM REVISTAS \\ CUSTOMIZADAS: UMA ANÁLISE DE MÉTRICAS E METODOLOGIAS USADAS POR EDITORAS BRASILEIRAS
}

\author{
Valéria Siqueira Castro Lopes* \\ valeriacastro@usp.br•Universidade de São Paulo, Brasil \\ Luiz. Alberto Bezerra de Farias ${ }^{* *}$ \\ lafarias@usp.br•Universidade de São Paulo, Brasil \\ Rosiane Simone Moro ${ }^{* * *}$ \\ rosiane.moro@gmail.com・Universidade Metodista de São Paulo, Brasil
}

RESUMO

O aumento da produção de conteúdo pelas empresas e a crescente busca dos profissionais de comunicação pela comprovação de resultados fez surgir no mercado a necessidade de maior conhecimento sobre técnicas de mensuração. Este artigo se propõe a analisar por meio de um estudo exploratório o processo de mensuração e avaliação em revistas customizadas em seis editoras brasileiras. Os resultados demonstram que as empresas ainda não incorporaram a mensuração de resultados em suas atividades, desconhecem as métricas e não possuem profissionais especializados no assunto.

Palavras-chave: revistas customizadas, métricas, mensuração e avaliação de resultados.

\section{INTRODUÇÃO}

Diante da multiplicidade de canais de comunicação e a crescente disseminação de informações está cada vez mais difícil para as empresas se destacarem diante da concorrência e atraírem a atenção do consumidor. A publicidade tradicional não funciona mais, o ambiente digital é dispersivo e os clientes não querem mais perder tempo com conteúdos meramente comerciais. Em um complexo cenário de acesso ao consumidor, as revistas customizadas acabaram ganhando representatividade e várias empresas investiram na produção de títulos próprios.

* Valéria Siqueira Castro Lopes é docente nos cursos de Graduação em Relações Públicas da Universidade de São Paulo (ECA-USP) e da Faculdade Cáper Líbero, Brasil.

** Luiz Alberto Bezerra de Farias é coordenador do Programa em Comunicação Social da Universidade Metodista de São Paulo (UMESP) e docente da Universidade de São Paulo (ECA-USP), Brasil

*** Rosiane Simone Moro é mestra em Comunicação pela Universidade Metodista de São Paulo (UMESP), Brasil. 
Em tempos de economia aquecida, forte lucratividade e verbas fartas, as customizadas proliferaram por conta do conteúdo atrativo, fotos de qualidade, material gráfico luxuoso e altas tiragens. Mas bastaram os primeiros sinais da crise econômica para os títulos começarem a desaparecer. Para liberar as verbas para antigos e novos projetos, as empresas passaram a exigir a comprovação de resultados e essa nova realidade do mercado trouxe à tona uma problemática que envolve praticamente toda a produção de conteúdo de marca na atualidade: justificar a eficácia de um produto de comunicação.

Apesar de a exigência ser recente, o debate em torno do tema não é novo. É possível encontrar uma crescente quantidade de estudos produzidos nos últimos anos tanto por profissionais de mercado quanto por acadêmicos e pesquisadores. Por outro lado, mesmo amplamente debatida e pesquisada, a prática da mensuração de resultados ainda é vista com reservas pelos profissionais de área (YANAZE, FREIRE e SENISE, 2013; FARRIS, BENDLE, PFEIFER e REIBSTEIN, 2012) e enfrenta vários obstáculos entre os produtores de revistas customizadas. O primeiro deles é a falta de profissionais com conhecimento no assunto (HUBBARD, 2015), que saibam explorar a diversidade das métricas e empregá-las de acordo com as estratégias da publicação. O segundo, é a necessidade de verba extra, uma vez que qualquer tentativa de quantificação de resultados requer a contratação de empresas ou especialistas para a sua execução. Em terceiro, está o fato de que os profissionais de comunicação, principalmente jornalistas, não têm o hábito de apresentar resultados de seus trabalhos porque muitos dos atributos imputados à atividade são considerados erroneamente como intangíveis (LUDWIG, 2005). Soma-se a isso, a inabilidade numérica, que dificulta a compreensão das métricas advindas das áreas administração, finanças e marketing, e o receio de uma punição, como demissão ou fim da ação, por conta de resultados negativos, e tem-se um cenário hostil à mensuração (GALERANI, 2006).

Atualmente, mostrar os resultados da revista customizada transformou-se em questão de sobrevivência. De um mercado extremamente aquecido, fomos surpreendidos com títulos cancelados, periodicidade e tiragens reduzidas ou produzidos apenas na versão digital. Sinal de que, há tempo, as empresas enxergam a revista como despesa ou commodity, além de não compreenderem sua função tática de trazer retorno para a organização (LUDWIG, 2005: 171).

É importante reforçar que a queda de produção de revistas customizadas não está atrelada apenas à dificuldade de mensuração de resultados. O mercado de revistas impressas em geral têm passado por uma crise e 
apresenta números cada vez mais inexpressivos ${ }^{1}$, com uma redução de $16 \%$ registrada em 2017. Em sua tese de doutorado, Crepaldi (2008: 24) apontou que existiam no Brasil 459 títulos auditados pelo Instituto de Verificação de Circulação (IVC).

Dez anos depois, temos apenas 62 títulos. Situação que pode ser atribuída aos problemas econômicos do país e também ao crescimento do mundo digital. Entretanto, o que impressiona no caso das revistas customizadas é o fato de a queda de tiragens, de periodicidade e até de circulação ocorrer justamente no momento em que as empresas necessitam aumentar o volume de vendas, conquistar novos consumidores e fidelizar clientes antigos, reforçando a tese de que os empresários as enxergam apenas como custo para a marca, uma espécie de presente dado aos clientes, que pode ser cortado sem qualquer prejuízo à lucratividade da organização.

\section{MARCO TEÓRICO}

O papel da comunicação como recurso para alcançar as metas das empresas de acordo com sua missão, visão e valores geraram demanda por uma atuação mais estratégica da área, focada em objetivos e resultados (KUNSCH, 2003: 103). Ao adotar o novo modelo de trabalho proposto pelo mercado, profissionais da área viram-se diante do dilema da prestação de contas de suas atividades. Essa necessidade fez com que, em um primeiro momento, dados pouco confiáveis fossem apresentados como resultados, revelando o despreparo das equipes de comunicação para lidar com essa nova realidade de mercado. A fragilidade dos relatórios apresentados aos clientes como resultado era, na verdade, apenas a quantificação das tarefas realizadas (LUDWIG, 2005; HON, 2005), sem conseguir justificar a eficácia da área. Provavelmente, tal falha origina-se na falta de planejamento estratégico, na ausência de definição de objetivos, na incorreta ou inexistente proposta de avaliação e mensuração de resultados e na desconexão entre os objetivos da área e os objetivos do negócio - fato ainda presente dentro das organizações na atualidade.

Estudos de Castillo-Esparcia e Villabona-Béltran (2018) sobre a utilização da avaliação por profissionais de comunicação baseados nos resultados do Communication Monitor na Europa, Ásia-Pacífico e América Latina mostram que a busca pela comprovação de resultados ainda é pouco utilizada e que

Apesar da queda geral, revistas crescem em digital. Matéria veiculada no Meio e Mensagem, em 19 de março de 2018, disponível em <http://www.meioemensagem.com.br/home/ultimas-noticias/2018/03/19/apesar-de-queda- geral-revistas-crescem-em-digital.html $>$. 
não houve mudanças significativas neste cenário nos últimos anos. Entre os principais problemas apontados está a falta de alinhamento entre os objetivos da área e os objetivos da comunicação e o pouco tempo dedicado à atividade, priorizando as tarefas operacionais. Poucos profissionais consideram a avaliação como tema prioritário na gestão da comunicação na Europa e Ásia-Pacífico, enquanto na América Latina esse tema não foi sequer citado pelos entrevistados no Communication Monitor nas duas edições já realizadas (2014- 2015, 2016-2017). Esse resultado explica o fato de muitos profissionais não realizarem a mensuração.

Embora a realidade comprove que a prática da avaliação e mensuração de resultados ainda é incipiente, o interesse dos comunicadores em atribuir valor às suas atividades vem de longa data. Likely e Watson (2013) fizeram um levantamento dos estudos e metodologias voltadas à área ao longo de 40 anos, entre 1973 e 2013, com o intuito de mostrar a evolução das teorias no decorrer deste período. Apesar do aparente aperfeiçoamento dos métodos, a pesquisa revela a complexidade do tema, sendo que vários acadêmicos ainda estão debruçados em suas teorias tentando adaptá-las ao mercado.

Volk (2016) obteve resultado semelhante ao analisar 324 artigos sobre avaliação e mensuração de resultados, publicados em inglês e divulgados em 12 revistas acadêmicas da área de relações públicas e gerenciamento da comunicação, entre os anos de 1975 e 2015. Seu estudo revelou a necessidade de desenvolvimento de novas teorias com uma visão multidisciplinar, obtenção de indicadores de resultados mais confiáveis, maior rigor metodológico e criação de estratégias para medição da comunicação de forma holística.

Ao visitar os artigos mais recentes sobre o tema, percebemos que há duas correntes em andamento. Uma parte deseja estabelecer padrões de avaliação para conectar a teoria com a prática (LIKELY, BUHMANN e GEDDES, 2018) e a outra pretende avançar no processo de mensuração associando os objetivos da área com os da organização (WATSON, 2013). O interessante desses trabalhos é que eles não são antagônicos, sendo as duas correntes complementares e essenciais para o progresso da atividade de mensuração.

Apesar de tratarmos de um objeto de pesquisa específico, o momento vivido pelas revistas customizadas não difere muito das outras atividades de comunicação, com resultados sustentados por números pouco representativos qualitativamente, como quantidade de e-mails de leitores ou acessos (page views) ao conteúdo na internet. Por serem consideradas imprecisas e/ ou superficiais, as métricas meramente quantitativas não são bem recebidas 
pelos profissionais da área financeira, responsáveis pela liberação das verbas para a produção das revistas e demais produtos de comunicação (CREPALDI, 2008: 28). O papel correto dos profissionais de comunicação é sair dessa atitude passiva e estabelecer por si próprio indicadores para serem medidos de acordo com os objetivos de cada ação. Em 2005, Ludwig (2005: 171) havia detectado que os métodos em uso não são eficientes e que os profissionais das empresas precisam de "metodologias mais claras de mensuração" para estarem dispostos a arcar com os custos do processo.

A diferença daquela época até agora está no fato de que atualmente os pesquisadores estão concentrados em apresentar mais propostas práticas do que conceitos metodológicos. Há vários estudos com efeito prático em andamento, capitaneados principalmente pelas instituições que começaram a pensar na avaliação e mensuração de resultados anos e anos atrás, como o Institute for Public Relations, nos Estados Unidos; o Chartered Institute of Public Relations (CIPR) e a International Association for the Measurement and Evaluation for Communication (AMEC), na Inglaterra, além dos esforços de vários pesquisadores e profissionais de mercado.

Castillo Esparcia e Alvaréz Nobell (2015: VIII) reforçam a necessidade do uso da avaliação e mensuração, principalmente com o advento da internet, que chegou ao mercado com variadas formas de mensuração: "Conhecer os resultados, tanto positivos quanto negativos, possibilita estabelecer prioridades, tomar decisões e previsões no planejamento e definir parâmetros para novas medições" (tradução nossa).

Galerani (2006, p: 45) menciona uma demanda crescente pela apresentação de resultados por conta da globalização, aumento da competitividade entre as empresas e da necessidade de aprimorar o relacionamento com os clientes, o que resulta em maiores investimentos na área de comunicação e, consequentemente, na necessidade de justificar os recursos empregados. Já Lopes (2005: 73) chama a atenção para a exigência dos profissionais mostrarem o quanto a área de comunicação "auxilia as organizações no alcance de seus objetivos de negócio, indicando seu valor econômico". Peddy (2017: 8) reforça que caso as agências não consigam comprovar resultados reais e tangíveis, relacionados a objetivos claros, qualquer dado apresentado perde o valor e compromete a verba do projeto.

Portanto, se há a necessidade de comprovar resultados e se tal comprovação agrega valor à comunicação, a mensuração precisa ganhar representatividade no planejamento estratégico da comunicação e passar a utilizar métodos 
de análise mais técnicos. Só assim será possível acabar com o estigma de que a comunicação não consegue apresentar dados confiáveis (MAIO, 2012: 16).

A necessidade de sair do discurso para a prática também é apontada no estudo PR 2020: The Future of Public Relations, realizado no Reino Unido pela CIPR, em 2011, que apresenta metas a serem atingidas até o final desta década (Castillo Esparcia e Alvarez Nobell, 2015: XIII). Entre elas, estão importantes reflexões sobre o uso da avaliação e mensuração de resultados, conforme abaixo:

- Existe uma grande necessidade de melhorar os métodos de avaliação para demonstrar o valor que as relações públicas proporcionam à organização.

- Os objetivos de avaliação devem ser interrogativos para serem mais significativos.

- A importância da avaliação contínua deve ser reconhecida em favor de um maior uso de ferramentas e situações.

- Padrões e diretrizes de avaliação global reconhecidos pelo setor são necessários para demonstrar a lucratividade das relações públicas; ocupar cargos nos conselhos de administração e demonstrar que são fundamentais para o negócio.

- É necessário desenvolver um sistema integrado e um conjunto de ferramentas significativas para medir o impacto e o valor das comunicações em relação aos objetivos do negócio; e que um padrão conhecido por todos os profissionais e suas equipes funcione.

- Devemos ser capazes de quantificar a contribuição profissional para o PIB e a economia.

- A reputação deve ser identificada como um ativo do saldo de resultados.

- O treinamento em mensuração e avaliação deve ser fundamental para as Associações e para a Universidade.

- A indústria deve trabalhar com os órgãos de medição e avaliação para o desenvolvimento de padrões. (Tradução nossa)

Os autores (2015: XVI) também explicam a necessidade de se criar uma agenda para colocar a mensuração de resultados em prática, afinal vários artigos, livros e blogs já demonstraram os inúmeros benefícios para a área, faltando apenas ações mais efetivas para concretizá-la. E usam como exemplo a lista de atividades propostas pelo presidente do Institute for Public Relations David Geddes: 
- Adotar um marco teórico conceitual comum e um conjunto de indicadores confiáveis e válidos.

- Estabelecer critérios e linhas de pesquisa em relações públicas, em mensuração e avaliação.

- Desenvolver mais e melhores modelos estatísticos.

- Padronizar um conjunto de indicadores, índices e modelos.

- Fundamentar nosso trabalho com base em experimentação e pesquisa.

- Melhorar a qualidade dos dados avaliados.

- Incentivar a formação profissional e a educação neste campo.

- Cooptar um conjunto de princípios éticos para pesquisa em relações públicas.

- Quebrar as barreiras que impedem a pesquisa de relações públicas.

- Quantificar e avaliar o impacto das relações públicas.

As análises acima confirmam a urgência de adotar métricas de avaliação de acordo com a realidade das atividades da área, apresentando casos de estudo reais sobre o tema. Schultz e Walters (1997: 33) lembram que a maioria dos métodos de mensuração foram criados entre as décadas de 1950 e 1960 e, portanto, não atendem mais às necessidades das áreas de comunicação e marketing da atualidade. É óbvio que a utilização de processos consagrados pela administração e marketing servem de subsídio e ponto de partida para o desenvolvimento de novos processos de medição, mas uma metodologia própria, que consiga lidar com a diversidade de ações da área, pode contribuir para a propagação das tarefas de mensuração.

Ao analisarem a avaliação da comunicação interna em empresas do Brasil, Canada, México e Estados Unidos, Meng e Pan (2012) descobriram que na falta de métricas específicas para a área, os profissionais de comunicação acabam adaptando, apesar de em menor escala, métodos de avaliação da área de negócios, como indicadores financeiros, índices de satisfação dos clientes e índices de qualidade de serviços. Por outro lado, a métrica mais citada pelos executivos entrevistados foi a pesquisa de feedback, seguida por pesquisa de grupo focal e pesquisa qualitativa. Apesar do objeto de nosso estudo ser voltado para a comunicação externa, as dificuldades apresentadas para a implantação de métodos de avaliação de resultados são similares a qualquer área da comunicação, independentemente do projeto a ser avaliado. 
É preciso, porém, atentar para os problemas que o uso incorreto da mensuração pode trazer para um projeto, como o risco de a comunicação focar-se exclusivamente em "objetivos quantificáveis" e ficar limitada a um nível tático e operacional (Galerani, 2006: 42), o alto custo do processo de medição impossibilitar a execução do próprio projeto (HUBBARD, 2015: 24) e a dificuldade de isolar o item avaliado de outras ações de comunicação (HON, 2005: 104), ocasionando uma leitura errônea da atividade. Até mesmo o uso de uma metodologia específica tem controvérsias: "Pretender um procedimento ou modelo padrão que não seja maleável é desrespeitar as lições que ensinam ser preciso adaptar as mensagens de comunicação à cada situação vivenciada e às características de cada segmento de público" (GALERANI, 2006: 58), resultando na utilização de ações e projetos de prateleira.

Outro obstáculo é o uso da tecnologia e inteligência artificial como ferramenta de medida para as atividades de comunicação. São programas padronizados que prometem avaliar o impacto da comunicação apresentando índices e pontuações específicas. Para Harary (2017: 14) essa premissa pode ser perigosa, uma vez que só a mente humana é capaz de ter pensamento crítico, interpretar completamente os resultados e analisá-los no contexto e objetivos das organizações.

Nesse contexto, considera-se irreversível o uso da tecnologia no processo de mensuração, porém, desde que seja restrito a procedimentos operacionais, como compilação e armazenamento de dados e execução de cálculos e fórmulas, enquanto a interpretação e análise sistemática dos dados deve ser realizada pelos profissionais da área.

Por último, há que se desmitificar a prática da mensuração. Se por um lado esse trabalho requer o manuseio de fórmulas, dados e demonstrativos financeiros, do outro temos alternativas mais simples. Hubbard (2015) que defende a adoção de técnicas de fácil compreensão e aplicação, criou em 1995 um método chamado Economia Aplicada às Informações, fundamentado no uso sistemático de cinco perguntas, a serem respondidas no início do processo de mensuração. São elas:

1. Qual é a decisão que essa mensuração deve apoiar?

2. Que (sic), realmente, está sendo mensurado?

3. O que isso tem a ver com a decisão que se deve tomar?

4. Que (sic) você sabe sobre o assunto agora? 
5. Qual é o valor de ampliar a mensuração do tema? (HUBBARD, 2015: 4)

O objetivo dos questionamentos é conseguir por meio das respostas dados que possam indicar decisões e comportamentos afetados pelos resultados da mensuração. Se ao final das indagações não for possível identificar efeitos concretos na organização, simplesmente não há motivos para fazer a mensuração. A autoavaliação inicial pode evitar desperdícios de esforços, tempo e verbas. Embora a técnica pareça superficial e imprecisa, percebe-se na adoção de linguagem mais coloquial uma tentativa de reduzir o medo e quebrar as resistências dos profissionais aos cálculos e conhecimento financeiro.

O autor ainda descontrói alguns dogmas da mensuração ao dizer que (1) seu problema não é tão incomparável, (2) você tem muito mais dados do que pensa, (3) você precisa de muito menos dados do que pensa, (4) há certa mensuração muito mais simples do que você pensa e (5) a mensuração só não deve ser feita quando seu custo exceder seus benefícios. Os pontos citados por Hubbard (2015: 38) refletem bem a realidade do ambiente das empresas e rebatem as principais justificativas dos profissionais para declinar da mensuração.

Os itens apontados pelo Institute of Public Relations mostram a necessidade da criação de um referencial teórico comum e indicadores confiáveis e válidos, uma vez que a diversidade de métricas e fórmulas de mensuração, decorrentes da administração, economia e marketing, dificulta o trabalho de quem precisa usá-las no dia a dia. Por outro lado, a variedade de ações de comunicação requer métodos de mensuração específicos, dificultando a simplificação da teoria. Como explica Maio:

Não existem fórmulas prontas para a escolha da metodologia mais adequada de avaliação em comunicação organizacional. Para que os resultados sejam medidos é fundamental testar, experimentar, aprender e aprimorar. O comunicador deve, no entanto, conhecer as possibilidades e, se possível, combinar várias técnicas. Metodologias quantitativas e qualitativas podem se complementar, unindo credibilidade dos números à riqueza dos depoimentos e observações, por exemplo. (MAIO, 2012: 22).

Escolher as métricas mais adequadas para analisar um projeto é o grande desafio dos profissionais de comunicação, principalmente por não existir uma métrica única nem perfeita (Farris et al., 2012: 3; YANAZE et al., 2013: 
95). Martin Klubeck (2012: 37), consultor de estratégia e planejamento na universidade americana de Notre Dame, defende que a seleção da métrica depende da descoberta da questão-raiz do projeto, ou seja, o que realmente pretende- se saber. A partir daí será possível estabelecer a melhor métrica, que, segundo o autor, deve ser composta por dados, medidas e informações, denominados por ele de história completa do projeto.

A escolha da métrica representa apenas uma parte do caminho a ser percorrido pela mensuração. Para, Klubeck (2012: 113) a compreensão de um projeto depende da interpretação correta dos dados, que pode, à primeira vista, não refletir a realidade. Como exemplo, cita o caso de um funcionário do serviço de atendimento ao consumidor de uma empresa com a menor quantidade de casos de clientes solucionados de sua equipe. Ao analisar os motivos da baixa performance, descobriu-se que tal funcionário, por ser o mais experiente da casa, ficava encarregado dos casos mais complexos e com maior dificuldade de solução, ou seja, a métrica tempo x quantidade não era a correta para avaliar o desempenho dessa equipe. "As métricas são uma ferramenta, um indicador - elas não são a resposta e podem ter múltiplas interpretações. Ouvi (vezes demais para o meu gosto) que as métricas devem 'guiar' decisões. Prefiro acreditar que as métricas devem 'informar' decisões" (KLUBECK, 2012: 113).

Uma vez que uma métrica pode levar a resultados errados, o autor sugere o uso da triangulação de informações, utilizando diferentes medidas, métodos, fontes de coletas e perspectivas (KLUBECK, 2012: 164-171), o que requer conhecimentos específicos sobre mensuração de resultados.

\section{METODOLOGIA}

A metodologia para o desenvolvimento deste estudo começa com a pesquisa bibliográfica no intuito de verificar o que foi publicado e estudado sobre o mensuração em livros e artigos das áreas de comunicação e marketing, além de sites especializados. A obtenção de embasamento teórico foi fundamental para elaborar os estudos de campo necessários para a coleta de evidências e facilitar a análise dos dados apurados, além de contribuir para a construção das reflexões finais do estudo em questão (ALVES-MAZZOTTI e GEWANDSZNAJDER, 1998: 182).

Nossa estratégia metodológica baseia-se na pesquisa qualitativa ancorada em estudo exploratório associado a entrevistas semiestruturadas, com amostragem reduzida e não representativa, realizadas com profissionais de 
seis editoras brasileiras especializadas na produção de revistas customizadas. A escolha dessa estratégia deve-se ao fato de que a mensuração de resultados em revistas empresariais é uma prática relativamente recente e é recomendável o estudo empírico para saber como os profissionais da área lidam com essa temática. O uso da entrevista semiestruturada realizada a partir de um roteiro pré- elaborado evita um leque muito aberto de respostas. Para a análise dos dados, a estratégia utilizada foi a construção de explanação, uma vez que nosso intuito é explicar um fenômeno e "estipular um conjunto de elos causais em relação a ele" (YIN, 2002: 140).

A relação das 500 maiores empresas do Brasil, divulgada pela revista Exame, foi tomada como ponto de partida para selecionar a amostra de pesquisa. Para detectar quais empresas, dentre as listadas na publicação, possuíam títulos customizados os sites das instituições foram consultados e identificadas 10 empresas com produção de revistas impressas para clientes. As publicações eram produzidas por nove editoras diferentes, sendo que seis delas aceitaram participar desse estudo.

A pesquisa foi realizada durante os meses de maio, junho e julho de 2018 de forma presencial nas quatro empresas estabelecidas em São Paulo e por telefone com as duas empresas instaladas no sul do país, todas sob contrato de confidencialidade, motivo pelo qual as editoras que fizeram parte da amostra de pesquisa são identificadas com nomes fictícios ao longo do artigo. Os entrevistados são proprietários das editoras ou profissionais que ocupam cargos de diretoria. Todos têm formação em jornalismo e possuem mais de 15 anos de experiência na edição e produção de revistas customizadas. As editoras são de grande e médio porte e editam em média sete títulos cada. Algumas possuem também títulos próprios vendidos em bancas. As publicações selecionadas de acordo com a lista da revista Exame pertencem a setores diversos, como automotivo, saúde, alimentício, transporte aéreo, varejo e bens de consumo.

\section{RESULTADOS}

A pesquisa de campo revelou uma grande diferença de modelos de negócio, impactando diretamente na forma de mensuração dos títulos. Observou-se que a cobrança por resultados está diretamente ligada ao montante investido pelo cliente e que o referencial teórico sobre avaliação e mensuração não está presente em nenhuma empresa. Também percebeu-se falta de conhecimento dos profissionais para falar sobre as métricas. A seguir, os tópicos abordados nas entrevistas serão detalhados. 


\subsection{O processo de mensuração de resultados das editoras}

Durante a pesquisa de campo foi encontrada apenas uma editora com processo de mensuração estabelecido, porém voltado integralmente para o modelo de negócio daquela publicação e meramente quantitativo. A maioria dos entrevistados diz ser importante apresentar resultados para o cliente, mas esbarram na falta de conhecimento para implantar o processo. Contraditoriamente, afirmam que a responsabilidade pela mensuração deve partir do cliente, o que os eximem de ter uma estrutura voltada para tal atividade dentro das editoras.

Não foram encontrados indícios de que a mensuração fizesse parte do briefing inicial da publicação e, nas poucas vezes em que aparece, é usada somente no final do processo, procedimento totalmente contrário ao apontado no referencial teórico sobre o tema, que estabelece como ponto primordial para a mensuração a definição de objetivos e resultados esperados na concepção do periódico. Apesar de não aplicarem qualquer método de avaliação e não conhecerem modos práticos de utilização, todos os entrevistados conheciam o termo mensuração e discorreram sobre o assunto de forma consciente e correta.

Percebe-se, portanto, desconhecimento sobre a prática da mensuração de resultados e também sobre o processo de planejamento estratégico da comunicação, composto pelas etapas de pesquisa, planejamento, implantação e avaliação (KUNSCH, 2003: 326), do qual a revista deveria fazer parte.

\subsection{Técnicas de mensuração utilizadas e em que momento são definidas}

Em decorrência da não utilização de métodos de mensuração não foi possível elencar as métricas usadas pelas editoras. Apenas a pesquisa de opinião foi citada, mas quando realizada resultava de uma iniciativa do cliente. Os entrevistados também apresentavam como resultado a quantificação de alguns dados, como tiragem e venda de publicidade, o que demostra o quanto as editoras ainda precisam avançar no assunto, principalmente em cenário de crise, uma vez que um processo de avaliação e mensuração de resultados consistente pode minimizar o impacto dos cortes no segmento de customizadas.

Nesse aspecto, mostra-se necessário a divulgação das metodologias e estudos acadêmicos em maior profusão, assim como a inserção da temática nas disciplinas dos cursos de comunicação. Também é preciso aumentar os estudos práticos sobre a mensuração, mostrando a aplicabilidade das teorias. 


\section{3 Frequência das mensurações, média de tempo empregado e profissional responsável}

Com exceção da editora Reciclato, nenhuma outra apresentou dado de frequência para a mensuração de resultados e quando realizada é feita de forma esporádica, sem o acompanhamento de um profissional focado nessa atividade. Os outros entrevistados não pretendem contratar profissional para essa função e tão pouco conhecem o perfil e as habilidades necessárias para a tarefa.

Esta situação referencia a necessidade da formação acadêmica voltada à mensuração de resultados, uma vez que sem profissionais capacitados dificilmente será possível disseminar a prática dentro das empresas.

\subsection{Participação do cliente no processo}

De modo geral, as editoras não são solicitadas a apresentar resultados a seus clientes, revelando falta de interesse pela mensuração. Dessa forma, acredita-se que esse comportamento não está restrito às revistas customizadas e estende-se aos outros produtos de comunicação.

No caso da editora Couché, o cliente faz pesquisas de opinião regularmente por conta própria e solicita à editora outros métodos de mensuração. No caso da editora Kraft, a apresentação de resultados foi solicitada com o intuito de decidir sobre a necessidade de continuidade do título (mensuração de resultado) e não para fazer alguma correção de percurso (avaliação de resultado).

Coincidentemente, os dois títulos são financiados integralmente pelos clientes, indicando que quanto maior o investimento na publicação, maior é o interesse pela mensuração de resultados. Os clientes das editoras que contam com o subsídio dos custos por conta da venda dos exemplares e/ou publicidade não solicitam qualquer análise de resultado.

\subsection{Análise da eficácia das ferramentas de comunicação}

Não foi possível obter informações sobre a eficácia das métricas pelo fato dos entrevistados não terem regularidade na aplicação da mensuração. O que se pode afirmar é que no caso da editora Couché, o entrevistado tem sérias restrições ao uso da pesquisa como fonte fidedigna de resultados, porém os comentários deixam claro que a pesquisa está sendo utilizada apenas para avaliar o produto revista e não os resultados do projeto como um todo, o que demonstra a necessidade de utilização de métricas conjuntas do processo de mensuração. 
Os entrevistados também não consideram a internet como fonte fidedigna de dados. Até utilizam as informações provenientes das interações com os leitores para desenvolver insights sobre o conteúdo, porém não quantificam as métricas digitais, como visualização de páginas, curtidas e compartilhamentos, nem usam esses dados formalmente.

\subsection{Dificuldades para a implantação dos métodos de mensuração}

Os entrevistados citaram três itens como os maiores empecilhos para a mensuração. O primeiro é a falta de conhecimento sobre as métricas. Percebe-se, inclusive, ao contrário da mensuração, que o termo métrica causa desconforto nos entrevistados, provavelmente por conta do desconhecimento e falta de habilidade para discorrer sobre o termo.

O segundo ponto abordado é o custo. Observa-se uma clara disposição das editoras em passar a responsabilidade pela mensuração de resultados aos clientes. As editoras foram unânimes em dizer que seria necessário cobrar um valor adicional do cliente para incluir essa proposta, o que encareceria os projetos, diminuiria a margem de lucro e dificultaria a negociação. Adicionalmente, citam a dificuldade de contratação de um profissional com conhecimento sobre processos de mensuração. Por outro lado, caso os clientes passassem a exigir pela demonstração de resultados, estariam dispostos a investir na contratação de um profissional, uma vez que poderiam cobrar pelo serviço por ser uma demanda da empresa patrocinadora do projeto.

\subsection{Ações tomadas de acordo com os resultados obtidos}

Como não realizam qualquer trabalho de medição, as editoras não conseguiram atribuir resultados práticos após a mensuração. Somente a editora Couché disse ter realizado alteração pontual no projeto e, de acordo com o entrevistado, a publicação já deixou de ser extinta devido à boa avaliação dos leitores. Nota-se aqui o quanto a avaliação e mensuração de resultados poderia contribuir para a melhora dos projetos de revistas customizadas caso fosse realmente praticada, ajudando- as editoras a serem mais assertivas em relação ao conteúdo da publicação, público-alvo e distribuição.

\subsection{Percep̧̧ão de valor das publicações pelas editoras}

As editoras são unânimes em afirmar que a revista ainda é uma boa fonte de comunicação com os clientes. Quando solicitados a discorrer sobre o que consideram como valor para a revista, os entrevistados citam vários 
atributos, como proximidade com o cliente, fidelização, manutenção de relacionamento, incremento de vendas, brinde simpático, melhora na imagem da marca, comunicação não invasiva, entrega de conhecimento e entretenimento, fortalecimento dos valores da marca, possibilidade de interação com outras mídias e divulgação de portfólio. Porém, as argumentações estão sustentadas em discursos, sem dados que confirmem que os títulos realmente cumprem essas funções.

Notou-se também que os itens acima não estão associados aos resultados que precisam ser alcançados com o projeto, ou seja, qual é o caminho necessário para atingi-los (metas), como saber se foram conquistados (mensuração de resultados) e se tiveram os resultados esperados (avaliação de resultados). Outro equívoco é não entrelaçar os objetivos da revista customizada com os objetivos macro da área de comunicação do cliente, deixando a publicação desconectada dos interesses da organização.

\section{DISCUSSÃO E CONCLUSÕES}

O objetivo deste trabalho foi mostrar o processo de mensuração de resultados realizado pelas editoras de revistas customizadas e nossa primeira impressão é que, apesar de o tema mensuração de resultados estar sendo estudado há pelo menos 40 anos (VOLK, 2016) no mundo e há 15 anos no Brasil, a implementação desses processos no mercado editorial ainda está em fase embrionária. O problema não advém apenas da compreensão dos métodos de avaliação e mensuração e está diretamente relacionado à falta de planejamento estratégico da publicação desde o início do projeto. Os objetivos das publicações apresentados na pesquisa são extremamente genéricos e relacionados aos atributos de uma revista customizada, quando na prática deveriam estar em sintonia com as metas dos clientes estabelecidas pela área de comunicação e com os objetivos macro da organização.

Outra problematização é o desconhecimento teórico sobre o tema. Há uma nítida confusão com os termos avaliação e mensuração de resultados, sendo na maioria das vezes considerados como sinônimos. Falta compreender que os dados coletados com mensuração dos resultados levarão à avaliação dos projetos e consequentemente apontarão os aprimoramentos necessários a serem adotados para a longevidade das publicações. Acredita-se que a resistência das editoras em adotar as práticas da mensuração esteja justamente relacionada com a falta de visão de os resultados apontarem as melhorias do projeto e não ser usada como forma de aprimoramento do trabalho realizado. 
Existe também uma nítida falta de sinergia entre os clientes e os profissionais das editoras quando o assunto é avaliação e mensuração de resultados. A responsabilidade sobre o processo deve ser todos os atores envolvidos na execução do projeto, uma vez que cada um possui dados específicos que quando agregados possibilitam a visão do todo.

Em tempos em que os projetos de revistas customizadas estão desaparecendo do mercado, a oferta do serviço de avaliação e mensuração por parte das editoras pode ser um diferencial em mercado fragilizado pela falta de demanda e ampla concorrência, assim como comprovação de que as revistas não são apenas um artigo de luxo oferecido pelas marcas sem qualquer retorno ou beneficio para a projeção do negócio.

Por fim, entende-se que há a necessidade de maior estudo sobre as métricas a serem usadas dos projetos. A dificuldade em conhecer os métodos de avaliação e mensuração resultados faz com que as empresas criem barreiras para a sua pratica, impedindo a sua utilização em larga escala.

\section{REFERENNCIAS}

ALVES-MAZZOTTI, A.J. e GEWANDSZNAJDER, F. (1998). O método nas ciências naturais e sociais: pesquisa quantitativa e qualitativa. São Paulo: Pioneira.

ANDERSON, F. W., HADLEY, L., ROCKLAND, D. and WEINER, M. (2009). Guidelines for settings measurable public relations objectives: an update. Disponível em: <https://instituteforpr.org/wpcontent/uploads/Setting_PR_Objectives.pdf>. Acesso em: 23 maio 2018.

CASTILLO ESPARCIA, A. y ÁLVAREZ NOBELL, A. (2015). Evaluación em comunicación estratégica. Madrid: Mc Graw Hill Education.

CASTILLO-ESPARCIA, A., y VILLABONA-BELTRÁN, D. (2018). Evaluación para demostrar la efectividad en comunicación y relaciones públicas. Una mirada a las prácticas profesionales desde los Communication Monitor. Communication Papers. 7. 137. 10.33115/udg_bib/cp.v7i15.22188.

CREPALDI, U. A. (2008). Metodologias de análise de retorno de investimento em comunicação institucional. Dissertação de mestrado. São Paulo: Universidade de São Paulo.

FARRIS, P. W., BENDLE, N. T., PFEIFER, P. E. e REIBSTEIN, D. J. (2012). Métricas de marketing. O guia definitivo de avaliação de desempenho de marketing. 2a ed. Porto Alegre: Bookman.

GALERANI, G. S. M. (2006) Avaliação em Comunicação Organizacional. Brasília: Embrapa.

HARARY, A. (2017). Measuring PR Performance across borders. In The PR professional's definitive guide to measurement. Disponível em http://prguidetomeasurement.org/, acessado em 06 de agosto de 2018.

HON, L. C. (2005). O mosaico da avaliação em relações públicas. Organicom: revista brasileira de comunicação organizacional e relações públicas. Ano 2, número 2. São Paulo: Gestcorp-ECA- USP, p. 97-115.

HUBBARD, D. W. (2015). Como mensurar qualquer coisa: encontrando o valor do que é intangível nos negócios. Rio de Janeiro: Qualitymark. 
KLUBECK, M. (2012). Métricas: como melhorar os principais resultados de sua empresa. São Paulo: Novatec.

KUNSCH, M. M. K. (2003). Planejamento de relações públicas na comunicação integrada. São Paulo: Summus.

LIKELY, F. and WATSON, T. (2013). Measuring the edifice - public relations measurement and evaluation practices over the course of 40 years. Sriramesh, K., Zerfass, A. and J Kim, J.N. (eds). Current Trends and Emerging Topics in Public Relations and Communication Management. New York: Routledge, 143-62.

LIKELY, F., BUHMANN, A. and GEDDES, D. (2018). Thoughts on recent developments in communication evaluation and measurement. Disponível em: https://instituteforpr.org/thoughts-recent-developments-communication-evaluation- measurement/>. Acesso em: 31 mar 2018.

LOPES, V.S.C (2005). O relações-públicas como gestor da imagem e a importância da mensuração dos resultados em comunicação corporativa. Organicom: revista brasileira de comunicação organizacional e relações públicas, Ano 2, número 2. São Paulo: Gestcorp- ECA- USP, p. 70-95.

LUDWIG,L. M. (2005). Avaliação de resultado: o desafio das agências de comunicação. Organicom: revista brasileira de comunicação organizacional e relações públicas, Ano 2, edição n o 2, p. 166-181.

MAIO, A. M. D. (2012). O desafio de desenvolver competências para avaliar resultados em comunicação empresarial. In Wilson da Costa Bueno (org.). Comunicação Empresarial: tendências e perspectivas. São Paulo: All Print.

MENG, J. and PAN, P. (2012). Using a balanced set of measures to focus on long-term competency in internal communication. Public Relations Review, volume 38, Issue 3, pages 484 - 490.

PEDDY, G. (2017). Getting started! How to create a measurement culture in your company. In The PR professional's definitive guide to measurement. Disponível em: $<$ http://prguidetomeasurement. org/>. Acesso em: 06 ago 2018.

SCHULTZ, D. E., and WALTERS, J. S. (1997). Measuring brand communication ROI. New York: ANA (Association of National Advertisers).

VOLK, S. C. (2016). A systematic review of 40 years of public relations evaluation and measurement research: Looking into the past, the present, and future. Public Relations Review 42, 962-977.

WATSON, T. (2013). Future trends in measurement and evaluation. Disponível em: < https://instituteforpr.org/future-trends-in-measurement-and-evaluation/>. Acesso em: 15 mar 2018.

YANAZE, M., FREIRE, O. e SENISE, D. (2013). Retorno de investimentos em comunicação - avaliação e mensuração. Rio de Janeiro: Senac; São Caetano do Sul: Difusão.

YIN, R. K. (2002). Estudo de caso: planejamento e métodos. Porto Alegre; Bookman. 